\title{
SALMONELLA EM ALIMENTOS PRODUZIDOS E COMERCIALIZADOS EM RESTAURANTES SELF-SERVICE EM MINAS GERAIS
}

CRUZ, L. F. ${ }^{*}$; SOARES, L. A. ${ }^{\text {; }}$ SOUZA, R. O. ${ }^{\text {; }}$ COELHO, M. B. ${ }^{1}$; GOMES, A. A.2; SOARES, J. O.2; OLIVEIRA, L. F.3; MAGALHÃES, J. T.3

${ }^{1}$ Alunos de graduação da Universidade Federal de São João Del Rei,

${ }_{2}^{2}$ Profissionais da diretoria de Vigilância em Saúde - Secretaria Municipal em Saúde/Divinópolis/MG, ${ }^{3}$ Professores da Universidade Federal de São João Del Rei

*e-mail: luisa_ferreira003@yahoo.com.br

\section{Resumo}

Atualmente, uma mudança nos hábitos alimentares da população tem sido causa do aumento do consumo de alimentos fora do domicilio. Diante disso, a inocuidade desses alimentos tornou-se uma preocupação, pois quando um controle sanitário não é obedecido, microrganismos patogênicos podem contaminar o alimento. Salmonella é um dos principais agentes envolvidos em intoxicações de origem alimentar e sua presença nos alimentos é relevante. Diante disso, oitenta e sete amostras de alimentos comercializados em restaurantes self-service do centro da cidade de Divinópolis, MG, foram analisadas quanto à presença deste microrganismo. Eles foram divididos em três grupos sendo, grupo A as saladas cruas, grupo B, alimentos cozidos e grupo C, alimentos com multi-ingredientes. Para análise, foi realizado o préenriquecimento em caldo não seletivo Lactosado, seguido pelo crescimento em caldo seletivo Tetrationato e, posteriormente, o plaqueamento em meios seletivos diferenciais, sendo estes, Agar Xilose-Lisina Desoxicolato, Agar Hektoen e Agar Salmonella Shigella. A confirmação do gênero Salmonella foi complementado pela análise das colônias típicas em tubos de Ágar Tríplice Açúcar Ferro. Os resultados foram interpretados segundo a RDC número 12 de 2011 da ANVISA. Das amostras analisadas, o grupo mais contaminado foi o das saladas cruas com $89,5 \%$ fora dos padrões estabelecidos, seguido pelos alimentos com multi-ingredientes com $66,7 \%$ e alimentos cozidos com $54 \%$. Esses resultados sugerem que a alta incidência de Salmonella em alimentos crus está relacionada ao fato deste alimento não ter sido submetido ao tratamento 
térmico, já que ela é termossensível, e/ou descuidos higiênico-sanitários. Sugere-se que a contaminação nos alimentos com multi-ingredientes possa ser devido a grande manipulação durante o preparo, e, portanto descuidos higiênicosanitários. Esses valores mostram a importância da aplicação das Boas Práticas de Fabricação no setor.

Palavras - chave: Salmonela, self-service, alimentos.

Agência de Fomento: FAPEMIG, CNPq, UFSJ. 